\title{
DISCIPLINAR EL ESPACIO, TERRITORIALIZAR LA OBEDIENCIA. LAS POLÍTICAS DE REDUCCIÓN Y DESNATURALIZACIÓN DE LOS DIAGUITAS-CALCHAQUÍES (SIGLO XVII)
}

\author{
DISCIPLINING SPACE, TERRITORIALIZING OBEDIENCE. THE POLITICS OF \\ REDUCTION AND DENATURALIZATION OF THE DIAGUITAS-CALCHAQUÍES \\ (17TH CENTURY)
}

\author{
Christophe Giudicelli
}

\begin{abstract}
En su primer siglo de existencia, la provincia de Tucumán fue teatro de una confrontación permanente. La resistencia de los grupos diaguitas-calchaquíes, ponía en jaque todos los intentos de poblamiento colonial de los valles interandinos. Con el tiempo, los hispanocriollos implementaron una estrategia radical para acabar con la autonomía indígena e integrar este enclave refractario en la esfera de la soberanía: la desnaturalización de los indios y su reimplantación total o parcial en un espacio de vigilancia encasillado y disciplinado.

Este trabajo pretende seguir la mutación de estas políticas de disciplinamiento abocadas a lograr el control de unas poblaciones signadas por la heteronomía desde el momento en que fueron atrapadas en la reorganización social y territorial del poder colonial. Las dos fases de guerra abiertas por los indios que consideraremos en este trabajo -el "gran alzamiento" de los años 1630-40 y la última guerra de los años 1658-64, obligaron a los agentes coloniales a revisar sus modalidades de dominación y de reclutamiento laboral, ideando nuevas formas de apoderamiento del territorio y de control de su población, reinscrita en unos dispositivos socio-espaciales más estrictamente vigilados.
\end{abstract}

Palabras claves: diaguita, calchaquí, Tucumán colonial, guerras indígenas, desnaturalizaciones, heteronomía.

The province of Tucumán was a theatre of permanent confrontation during its first century. The resistance of the DiaguitasCalchaquíes Indians stalled all colonial attempts to settle in the inter-Andean valleys. The Hispano-Criollos progressively implemented a radical strategy aiming to end indigenous autonomy and to integrate that unyielding enclave into the nation: the denaturalization of the Indians and their total or partial relocation into a disciplined and controlled space.

This paper follows the development of these disciplining politics intended to achieve control over populations characterized by heteronomy, since the moment they were caught in the social and territorial reorganization of colonial power. The two moments of open conflict considered in this work -the 1630-40's "Great Uprising" and the last 1658-64 war-forced the colonial agents to reassess their forms of domination and recruitment of workers and to enforce new ways of seizing the territory and of controlling the population within more strictly disciplined socio-spatial schemes.

Key words: Diaguita, calchaquí, colonial Tucumán, indian wars, denaturalization, heteronomy.

Este trabajo pretende enfocar, para el caso concreto de la primera mitad del siglo XVII en los valles andinos de Tucumán, en la tensión dialéctica mantenida entre, por un lado el diagrama colonizador -vector de cuadriculación territorial y de disciplinamiento sociopolítico-y, por el otro, la resistencia de los grupos diaguitas-calchaquíes. Esta resistencia se entiende no solo como mera reacción al embate colonial, sino como producción y reproducción de autonomía, más particularmente como afirmación de una territorialidad no sujeta a las coordenadas espaciales y políticas definidas por las instancias coloniales.

El estudio se centrará esencialmente en las consecuencias de los dos eventos históricos mayores que sacudieron la región en la primera mitad del siglo XVII, es decir lo que se ha dado en llamar los alzamientos calchaquíes, primero el "Gran Alzamiento" de los años 1630-1640, y luego la guerra de los años 1658-1665, desencadenada

CNRS-CREDA UMR 7227 (équipe CHACAL) / Université Rennes 2, Francia. cgiudicelli.terra@ wanadoo.fr

Recibido: mayo 2017. Aceptado: diciembre 2017.

http://dx.doi.org/10.4067/S0717-73562018005000201. Publicado en línea: 20-febrero-2018. 
en parte por Pedro Bohórquez, alias "el Inca del Tucumán". Hemos privilegiado estas dos secuencias históricas porque constituyen un momento de aceleración y de mutación dramática del proceso de territorialización colonial. Veremos como el fracaso de la militarización del espacio, que condujo hacia una política de desnaturalización masiva de las poblaciones vencidas, marcó un giro definitivo en la estrategia de colonización hispanocriolla. El modelo de territorialización-disciplinamiento, privilegiado hasta entonces, cedió el paso a una ocupación lisa y llana del territorio interandino combinado con una relocalización sistemática de sus habitantes en espacios coloniales ubicados fuera del valle, según una lógica en la que los imperativos productivos ya primaban sobre los requisitos políticos. Veremos también, apoyándonos en los estudios de caso más recientes como ciertos grupos desnaturalizados si bien no lograron mantener totalmente su autonomía política, pudieron rearticular su territorialidad mediante en particular una estrategia de doble residencia ${ }^{1}$.

\section{El Modelo de Territorialización y sus Límites}

Desde los primeros tiempos, la obsesión de las autoridades de Tucumán giraba en torno al "poblamiento", es decir la fundación de villas o ciudades que, a su vez permitiesen incorporar a los indios en las estructuras de producción, mediante las instituciones clásicas de la mita y la encomienda. Se trataba de una práctica general en estas provincias periféricas, que sería sistematizada por las ordenanzas de poblamiento de Felipe II de 1573 (en Morales Padrón 1979:489-518) y por la política general del Virrey Francisco de Toledo. Esta imposición del orden colonial debía plasmarse en una cuadriculación del espacio y una implementación de dispositivos concretos y simbólicos de control: los pobladores recibían mercedes de tierra y encomiendas de indios, lo cual sentaba la base de una "espacialidad colonial" (Vázquez 2011).

Como es bien conocido, esta política fue interrumpida dramáticamente a principios de los años 1560 , cuando una ingente coalición indígena echó literalmente a los hispanocriollos de la casi totalidad de sus incipientes ciudades: Londres (en los alrededores de la actual Belén, Catamarca), Cañete (la primera San Miguel de Tucumán), Nieva (la primera Jujuy) y, sobre todo, la primera Córdoba, cerca de la actual San Carlos, en los valles Calchaquíes. La destrucción de esta última ciudad tendría consecuencias fundamentales para la cristalización de la imagen de los indígenas (Giudicelli 2015), asociada de ahora en adelante a las supuestas cualidades bélicas del cacique de Tolombón, Juan Calchaquí. En primer lugar porque, a diferencia de las otras, sus vecinos no pudieron escapar del cerco y sufrieron la suerte de los vencidos: los hombres fueron masacrados mientras que las mujeres y los niños fueron repartidos entre los vencedores. Segundo, porque mientras que las demás ciudades pudieron reconstruirse en las décadas siguientes, todos los intentos por relanzar el poblamiento colonial en el corazón del ya "valle de Calchaquî" fracasaron estrepitosamente: en 1577, y luego en 1630.

Es de recalcar este contraste porque marca la impotencia de los agentes coloniales por controlar una región importante desde un punto de vista productivo y estratégico para el espacio disciplinado de la provincia. A partir de finales de los años 1580 , con la llegada del gobernador Juan Ramírez de Velasco, que disponía de más medios para ello, se relanzó el proceso de poblamiento. Se multiplicaron las fundaciones: La Rioja (1591), San Salvador de Jujuy (1593), Madrid de las Juntas (1592), y Londres sería asimismo refundada en 1607 (Quiroga 2012). Paralelamente, se reforzó la presión sobre los grupos indígenas que habían logrado mantener su autonomía (Carmignani 2013). El caso más llamativo tal vez sea el fortalecimiento de la ciudad de Salta. Fundada en 1582 bajo el nombre de San Felipe del Río de Lerma, era hasta entonces un paraje muy inseguro en el que las autoridades lograban mantener a duras penas una presencia mínima. En 1588, Ramírez de Velasco organizó una campaña de varios meses en los valles Calchaquíes, logrando someter parte de la población indígena -los diversos grupos subsumidos bajo el apelativo "pulares" (Giudicelli 2013a)- y establecer un modus vivendi o una paz armada con los demás.

En resumen, dos porciones del espacio vallisto cayeron entonces paulatinamente bajo la dominación colonial: el espacio "pular", en el norte y la tierra que iban a llamar "de los diaguitas", para disgregarla del espacio de infidelidad calchaquí, hacia el sur.

El caso de los pulares es interesante porque durante varias décadas, presentaron el ejemplo de una "territorialización colonial feliz", por decirlo de alguna manera (Giudicelli 2011a). En poco tiempo, esos grupos diaguitas iban a diferenciarse de los demás por su disciplinamiento o, para hablar en términos de la época, por su calidad de "indios domésticos". Para los primeros años del siglo XVII, vivían en reducciones, cumplían con las exigencias de sus encomenderos, acudían a sus turnos de mita, recibían favorablemente las primeras misiones volantes de los jesuitas y llevaban hasta en su cuerpo las marcas microfísicas del poder: "visten 
al modo de los indios del Perú" y se cortaban el pelo (algo que revestía una gran importancia para los diaguitas (Torreblanca 1999 [1696]:74; Torres 1601 en Levillier 1930:365-369). Más aún, con el tiempo, se iban a convertir según uno de sus encomenderos en "la mayor fuerza de indios amigos", participando junto con las tropas hispano criollas en las columnas de represión de los años 1630-1640 contra sus vecinos ${ }^{2}$.

En el sur de la región, en la jurisdicciones de La Rioja y Londres, si bien no parece tan claro y rápido el proceso de disciplinamiento ${ }^{3}$, sabemos por lo menos que ya se había emprendido con cierta eficacia un proceso de reorganización territorial ${ }^{4}$, con traslados de indígenas desde sus tierras a las de su encomendero, o a algún pueblo de reducción (De la Orden Peracca 2006; Farberman y Gil Montero 2002; Quiroga 2012; Vázquez 2011).

El rompecabezas para las autoridades coloniales seguía siendo el del valle de Calchaquí, es decir la zona gris comprendida entre estos dos espacios más o menos controlados, tanto más cuanto que los contactos de sus habitantes con los de las zonas cuadriculadas eran permanentes. La delimitación del valle de Calchaquí conservó una notable regularidad desde finales del XVI y las campañas de deportación de mediados del siguiente: unas treinta leguas, desde la "raya de los pulares", que marcaba el límite del avance colonial al norte (Giudicelli 2011a) y pasaba entre la reducción de Atapsi, probablemente en las inmediaciones del actual pueblo salteño de Seclantás, y el primer pueblo calchaquí de Pompona hasta Punta de Balasto, en el valle Yocavil que a su vez marcaba el límite norte de "la provincia de los diaguitas", es decir la jurisdicción de La Rioja y, después de su refundación, de Londres (Moyano Aliaga 1991:3739). La definición del "valle de Calchaquî" responde a una lógica totalmente heterónoma: el criterio de delimitación no respondía en absoluto a criterios políticos o culturales -y sería por demás imprudente fijar fronteras de tipo étnico- sino a cuestiones que remiten siempre, en última instancia, a la economía del espacio colonial (Giudicelli 2007). Plasma ante todo la impotencia colonial frente a la resistencia de los diferentes grupos comprendidos en sus límites territoriales y que lograron durante mucho tiempo conservar su autonomía política y su independencia territorial.

El caso es que desde principios del siglo XVII, el enclave Calchaquí se definía siempre negativamente, por ausencia, como una amenaza en actos contra la territorialidad colonial. Tenía las características una suerte de agujero negro capaz de disolver los efectos de la soberanía europea.
Los síntomas que preocupaban a todos los agentes coloniales se pueden resumir en algunas líneas:

- Fracaso del reclutamiento laboral: los indios genéricamente llamados calchaquíes, muchos de los cuales habían sido encomendados en fechas tempranas, no servía, y, salvo en algunos periodos muy cortos, no cumplían con sus turnos de mita (Boixadós 2011b).

- Fracaso de la Compañía de Jesús: la territorialización jesuítica, típica en esas tierras de frontera (pensemos en el Paraguay o en el norte de la Nueva España) fracasó casi inmediatamente en el valle. Hacia 1624, los jesuitas tuvieron que abandonar la misión que tenían en San Carlos, después de 11 años de residencia en el valle, "por falta de sustento"5.

- Permanencia de un foco de autonomía sobre el que los agentes coloniales no tenían ningún control. Abundan las denuncias de cabildos y particulares contra ese "refugio de delincuentes y forajidos", en el que se van a refugiar todo tipo de rebelde en ruptura de obediencia colonial: indios de encomienda, delincuentes condenados por la justicia, esclavos fugados, etc. ${ }^{6} \ldots$ Era una zona peligrosa de transitar.

\section{El Gran Alzamiento: militarización del espacio, reducciones y primeras desnaturalizaciones}

Fue en este contexto cuando se desató el segundo gran período de guerra abierta que se extendió a toda la región andina, desde el sector pular hasta la ciudad de La Rioja y las tierras en principio más controladas de su jurisdicción, en particular el valle de Famatina.

El detonante fue el saqueo y la destrucción en 1630 de la estancia de un vecino de Salta, Juan Ortiz de Urbina, ubicada no muy lejos del actual pueblo salteño de Seclantás. En esta ocasión, un grupo de indios entre los cuales se encontraban calchaquíes de la estricta obediencia -si nos atenemos a la geografía de control colonial- y otros considerados pulares mataron al encomendero, a su cuñado, a otro español, a un franciscano que tuvo la mala suerte de pasar por ahí y a muchos indios de servicio. Por si fuera poco, se llevaron a varios rehenes, entre los cuales a "cuatro doncellas españolas" "Carta del gobernador Felipe de Albornoz al Rey", en Levillier 1930, III:411-417). El ataque motivó unas represalias fulminantes por parte de las autoridades coloniales, en las cuales fueron implicados los indios amigos pulares ("Carta del gob. de Tucumán Felipe de Albornoz, 29-04-1631", en Rodríguez Molas 1985:148 y ss.). Lo que en un principio no pasaba de un conflicto local degeneró en una guerra que se extendió por más de diez años al conjunto de la región interandina. 
Uno de los motivos generalmente aducidos para explicar el ataque contra la estancia de Urbina fue que éste habría descubierto ricas vetas de plata y que quería explotarlas (Torreblanca 1999 [1696]; Lozano 2010 [1745]:1030). Faltan datos para corroborar esta afirmación. Lo que en cambio está muy documentado es que en ese mismo momento el gobernador Albornoz estaba ultimando los preparativos para establecer una ciudad permanente en el valle, más o menos donde se elevaba Córdoba de Calchaquí en 1562 y donde ya se había querido reconstruir en 1577 (Cartas del gob. Albornoz, en Larrouy 1923:56-59 y 60-63). Como incentivo, había conseguido que los encomenderos de Salta y San Miguel de Tucumán que tuviesen algún título sobre los indios del valle de Calchaquí renunciasen a un tercio de las mismas ${ }^{7}$, en provecho de los nuevos vecinos de la ciudad por construir, que debía llevar el nombre de Nuestra Señora de Guadalupe de Calchaquí (Carta del gob. Albornoz 01-03-1633, en Larrouy 1923:75) ${ }^{8}$.

En total se crearon 19 nuevas encomiendas. Era un buen negocio para todos, que ya había tenido éxito en la refundación de Londres ${ }^{9}$ : los nuevos encomenderos mejoraban su estatus y lo viejos podían esperar sacar por fin algún beneficio de unas encomiendas hasta entonces poco más que virtuales. La nueva ciudad nunca pasó de ser un fortín de madera precario, aislado en tierra de guerra, que sus ocupantes no tuvieron más remedio que abandonar a los pocos años porque los indios los fueron diezmando cada vez que se alejaban, y porque nunca pudieron sobrevivir sin ayuda externa ("Carta del gob. F. de Albornoz, 16-031634”, en Larrouy 1923:135-136) ${ }^{10}$. La fundación del nuevo poblado no dio el resultado esperado: el intento por someter a los indios del valle había empeorado la situación. Hacia el norte, los Pulares habían tenido que ser evacuados del otro lado de la sierra, en el valle de Salta, para ponerlos a salvo de las represalias... y para que no cambiasen de alianza y segundasen a sus mejores enemigos ("Carta del gobernador F. de Albornoz 01-03-1633", en Larrouy 1923:87 y ss) ${ }^{11}$.

Mientras tanto, hacia el sur, la guerra se había propagado como un reguero de pólvora, siguiendo una cadena de alianzas que implicó en muy poco tiempo a todos los grupos del área "diaguita". En 1632, la ciudad de Londres volvió a ser arrasada y sus ocupantes tuvieron que escapar en las peores condiciones huyendo del fuego enemigo, para terminar encerrándose en la de La Rioja, a la que los indios de Capayan y Famatina pusieron cerco durante varias semanas (Lozano 2010:1032-1036; Montes 1961). La ciudad se pudo salvar gracias al socorro mandado desde Córdoba y Cuyo. Al final del año 1632, además del valle de Calchaquí, toda la jurisdicción de Londres y de La Rioja se encontraba sublevada, la autoridad colonial arrinconada en algunos puntos fortificados sobre las ruinas de estancias y reducciones, en particular en Nonogasta, Machigasta, y Pomán (“Carta del gob. Albornoz 01-03-1633”, en Larrouy 1923:87 y ss).

Esta situación se iba a perpetuar durante varios años, generando una nueva organización territorial dictada por la guerra: todo lo que se parecía de cerca o de lejos a un establecimiento español había sido arrasado (casas, iglesias, reducciones), muchos colonos, entre ellos dos sacerdotes, habían sido ejecutados. Los alzados habían tomado incluso medidas simbólicas muy fuertes: Juan Chelemín, cacique de los malfines, considerado por los hispano criollos como líder de todo el movimiento, remedaba la autoridad colonial: se lo acusó de tener en su pueblo "horca y árbol de justicia levantado en que ahorcaba los indios gente que le parecía eran afectas a los españoles" ${ }^{\prime 2}$. Al parecer, hubo incluso casos de ejecuciones de mujeres indígenas que habían tenido trato carnal con los españoles (Carta Anua 1632-1634 1990; Lozano 2010 [1745]:103) ${ }^{13}$. Frente a la ruina de todo lo que había constituido la base concreta del disciplinamiento territorial, los agentes coloniales se tuvieron que adaptar, reorientando su acción, recentrándola en concreto sobre núcleos militarizados. Entre 1632 y 1637, además de los fortines ya evocados, se crearon dos fuertes de importancia: el de Andalgalá, en el corazón del territorio más conflictivo, debido a la alianza entre malfines y abaucanes, las dos facciones más poderosas en ese momento (Schaposchnik 1997), y el de San Blas del Pantano en el Valle Vicioso, para proteger La Rioja (Lozano 2010 [1745]:1042). Lo que interesa aquí, más que el aspecto meramente militar, es que la reconstrucción de la obediencia se dio en gran parte a partir de estos fuertes, mediante una concentración de los grupos que "bajaban de paz" en su entorno, donde quedaban reducidos territorialmente. De hecho, recién a partir de 1637, con una conflictividad de baja intensidad, por así decirlo, los agentes coloniales retomaron la iniciativa. Para restaurar su dominación y relanzar un proceso de producción colonial totalmente estancado, se implementó una política inédita en la región de desplazamiento masivo de población y, como lo acabamos de ver, de concentración. En el fuerte del Pantano, en particular, se llegó a reducir entre 2.000 y 3.500 personas según las fuentes (Montes 1961:152), con contingentes algo menores en Andalgalá y Famatina. En pocas palabras, ya que no se había podido disciplinar a los indios en su territorio, se los desplazaba hacia unas zonas disciplinadas, o disciplinarias. Ya tenemos aquí un anticipo de la política que sería sistemáticamente aplicada en los años 1659-1665 con los grupos calchaquíes, aunque con otra lógica y un efecto de fragmentación muy superior.

Para retomar posesión del territorio, las columnas de pacificación habían echado mano de medidas espectaculares, clásicas de este tipo de campañas: habían sembrado los caminos de cuerpos ahorcados y mutilados, clavado cabezas de supuestos responsables 
enpicas, organizadoejecuciones públicas particularmente atroces en el lugar de sus delitos (Carta anua de 16321634 1990:71-72). El hecho más representativo de esta reapropiación simbólica del territorio fue el destino del cuerpo supliciado de Juan Chelemín. Al igual que el cacique de Famatina, Coronilla, unos años antes (Lozano 2010 [1745]:1040), fue descuartizado en su pueblo de Hualfín, pero se le dio a su ejecución una dimensión ejemplar aún más llamativa: después de muerto, Chelemín fue expuesto en partes en los lugares más paradigmáticos de la nueva geografía de control. Cuenta Pedro Ramírez de Contreras, el caudillo que lo apresó que

[...] le condenó a muerte e hizo cuartos en su propio pueblo y horca y clavó su cabeza en el rollo de la ciudad de La Rioxa [...] y en el de esta [Poman] asimesmo mandó clavar su brazo derecho para escarmiento y ejemplo de otros $^{14}$.

Como vemos, el disciplinamiento de las poblaciones vencidas pasaba por un nuevo tipo de territorialización fuera de su "natural", bajo una vigilancia mucho más estricta. También es cierto que esta política de concentración respondía a un estado de la situación particular: después de esos largos años de guerra, todas las infraestructuras coloniales quedaban por reconstruir, y, por si fuera poco, había vuelto a desaparecer Londres, la avanzada más cercana al Valle Yocavil, perteneciente al área de insumisión Calchaquí. Durante un tiempo, las relaciones coloniales se dieron en este marco algo peculiar: los encomenderos iban a buscar a sus encomendados allí y los jesuitas, quienes habían participado en las campañas militares y en las operaciones de pedagogía por el terror volvieron a oficiar también en este contexto, primero en el fuerte del Pantano, antes de retomar su labor en el Valle de Calchaquí (Torreblanca 1999 [1696], Carta del Provincial de la Cía. de Jesús Fco. de Lupercio de Zurbano a SM, en Pastells 1912, II:96-97). Hecho notable, porque anticipa las desnaturalizaciones que se iban a generalizar después: los grupos más reacios al nuevo disciplinamiento, fueron desplazados incluso varias veces y muy lejos de sus tierras. Tal es el caso de malfines y abaucanes, estudiado por Sosa Miatello y Lorandi (1991) y luego por González Navarro (2009): primero concentrados en Andalgalá, fueron trasladados al fuerte del Pantano. Después de unos años se los desplazó de nuevo al pueblo del Guaco, cerca de La Rioja, antes de destinarlos a la ciudad de Córdoba en 1647.

Sintomáticamente, este alejamiento de un grupo relativamente importante venía justificado por la incapacidad de los agentes coloniales por retenerlo efectivamente en su lugar de confinamiento. Varios testigos reportan en efecto que "se vuelven a su natural", y temen que quieran retomar la guerra, por la estrecha relación que mantenían con los grupos yocaviles, con los que tenían relaciones de parentesco y de alianza, y quienes seguían alentando la guerra (Boixadós 2011b; Schaposchnik 1997). Esta tendencia a desertar de las concentraciones y a volver a su tierra (Quiroga 2010) no era, ni mucho menos una excepción: se daba en todas las reducciones militarizadas.

\section{Cambio radical de lógica: las desnaturalizaciones de 1659-1665}

En el valle de Calchaquí propiamente dicho las últimas fases de la guerra habían desembocado en un statu quo ante, se había interinado finalmente el fracaso del enésimo intento de asentamiento y enterrado el proyecto de sostener el fuerte de Nuestra Señora de Guadalupe, que fue abandonado de forma definitiva. Lo único que se había logrado, a cambio de un cese de las malocas españolas, era un curioso pacto con los grupos más poderosos del centro del valle, Tolombones y Paciocas: éstos se comprometían a unas prestaciones, pero decidirían sobre las circunstancias y la conveniencia de las mismas (Boixadós 2011b). Huelga decir que este acuerdo se aplicó a mínima... (era una manera de legalizar su mala voluntad). En el norte del valle, el desplazamiento forzado de los pulares había empeorado la situación de los colonos: la zona se encontraba bajo la vigilancia de los alzados, y los mismos pulares mostraban un creciente descontento porque además de encontrarse fuera de sus tierras, en las inmediaciones de la ciudad de Salta, no se les había cumplido una serie de promesas. Tardarían varios años en regresar a sus reducciones dentro del Valle, con una confianza bastante menguada en sus encomenderos y en los hispanocriollos en general.

De modo que en las décadas 1640-1650, el valle de Calchaquí retomó en gran medida su estatuto de rompecabezas para las autoridades:

- El paso por el valle era tan inseguro como antes.

- Seguía siendo un lugar de refugio ideal para individuos y grupos en ruptura de obediencia.

- El nuevo intento misionero, emprendido a partir de 1643 con base en Santa María, en el valle de Yocavil, y San Carlos, en las inmediaciones de las malogradas fundaciones anteriores daba pocos frutos, y es poco decir. Basta con leer la correspondencia amarga de los misioneros para convencerse de ello: está plagada de quejas e insultos contra sus neófitos quienes, según rezaba la Carta Anua de 1653-1654 "[...] no menos en lo físico que en lo moral, imitan en todo las costumbres de los brutos más indómitos. [...]" (en J. Cortesão 1952 II:137).

En semejante panorama, la irrupción del personaje novelesco de Pedro Bohórquez alias "el Inca del 
Tucumán" (Lorandi 1997; Piossek Prebisch 1976) precipitó el desenlace final y la elección de una política radical de deportación sistemática.

A pesar de la innegable fascinación que ejerce el personaje, no creemos que haya que sobreestimar su peso propio en los hechos, dada la profundidad histórica de la confrontación que existía antes de su llegada, y siguió en términos no muy distintos después de su desaparición del escenario. Lo que sí, si bien él no creó una situación realmente nueva, sus dobles juegos propiciaron un final dramático. Se encontró involucrado en por lo menos dos hechos fundamentales:

- Permitió una recomposición de alianzas en torno a su figura que difícilmente hubiera podido concretarse de otro modo. Alianzas que articulaban a la vez los grupos pulares y los del valle de Calchaquí, en términos más que delicados desde la guerra anterior. - Organizó la expulsión manu militari de los jesuitas en 1658, arruinando el único dispositivo de contención/disciplinamiento de los indios que quedaba en el Valle.

- Por fin queda un último aspecto muy de tomar en cuenta. El levantamiento puso al gobernador Mercado y Villacorta en una situación de desprestigio muy grave. Su tolerancia con las excentricidades de Bohórquez -lo había dejado incluso llevar el título de Inca- había desembocado en una nueva ofensiva masiva de los grupos calchaquíes. Tamaño desprestigio obligaba al gobernador a "hacer méritos", a obtener resultados a toda costa. Para contrarrestar el efecto nefasto de la ofensiva indígena en las mismas puertas de San Miguel y de Salta, tomó una decisión drástica: la de deportar a los habitantes de todos los pueblos del Valle de Calchaquí.

Se elaboró un auténtico plan de disciplinamiento por el vacío que preveía un rastreo sistemático de todos los pueblos del valle y sus anexos, una concentración de toda la población vencida y su dispersión en lugares apartados.

Solo quedaba un pequeño detalle: vencer a unos indios que habían logrado resistir con éxito a 130 años de presión colonial, y que acababan de reconstituir poderosas alianzas maltrechas por las guerras pasadas. El problema recurrente de las autoridades era la dificultad por reclutar soldados. Por si fuera poco, el problema se planteaba con renovada fuerza esta vez: al contrario de lo que había pasado en la década de 1630, los grupos pulares se encontraban complicados en la conspiración urdida por Bohórquez, y no se podía contar con ellos para la guerra. Para motivar a los españoles pobres para que alquilasen su fuerza de trabajo en las columnas de pacificación, había que encontrar un aliciente suficiente. Mercado tuvo una ocurrencia que le permitió reunir tercios motivados. Tomando serias libertades con la legalidad, cambió el modelo económico de las malocas. Tomó la responsabilidad de extender a la situación presente del Tucumán una Real Cédula emitida cuarenta años antes para el caso específico y exclusivo de los Payaguás y Guaycurúes que hostigaban las ciudades paraguayas de Asunción y Concepción del Bermejo ("Carta del gobernador A. de Mercado y Villacorta, 05-05-1661”, en Larrouy 1923:237):

[...] hice notoria [...] una cédula de VM despachada en favor de las provincias del Paraguay y permitiendo el servicio personal de las piezas que se aprisionaron en la guerra de cierta parcialidad de indios cuyos delictos de quemar iglesias, invadir las fronteras y buscar con robos las jurisdicciones hallé muy parecidos a los que estos bárbaros cometieron en su alteración y en el rompimiento de la guerra ${ }^{15}$.

Se trataba ni más ni menos de institucionalizar el financiamiento de la campaña mediante la atribución de piezas sueltas y sobre todo de encomiendas salvajes a los participantes a las entradas, en clara contradicción con todas las reglas legales, incluso dentro del marco de la "justa guerra" (Doucet 1982, 1988; Giudicelli 2013b). Dicho de otro modo, se propiciaba un regreso a una práctica de razzias esclavistas a gran escala. Hubo algunas protestas oficiales contra esta interpretación extensiva de una Cédula que nada tenía que ver con el Tucumán, y contra las medidas tomadas. El Consejo de Indias le reprochó incluso el haber "repartido más de mil esclavos"16 (AGI, Charcas 122, exp. 44). Con todo, dado el éxito del plan, las máximas autoridades terminaron avalando lo que había dispuesto Mercado.

En los hechos, logró reunir una tropa enorme y entusiasta venida de todas las ciudades de la provincia, pero también de Santa Fe, y logró la "desnaturalización" de la casi totalidad de la población aún autónoma del valle. La medida se llevó a cabo en dos campañas, una en 1659 y otra en 1665-66:

- Durante la primera, vació toda la región comprendida entre las reducciones pulares -quienes deportados también- y el pueblo de Quilmes, con la excepción de los grupos de Tolombón, Colalaos y Paciocas, que negociaron su redición e integración como tropas auxiliares a cambio del derecho de permanecer en sus tierras.

- Otra en 1665-66, que abarcó a los Quilmes y a todos los grupos del valle Yocavil, pero también a los Tolombón y Colalaos, a los que les fueron dadas tierras del otro lado de la Sierra (Figura 1).

No es éste el lugar para entrar en el detalle de un evento que por otra parte ya ha sido abundantemente estudiado (Boixadós 2011a; Cruz 1997; Giudicelli 2013; Lorandi y Boixadós 1987-88; Palermo y Boixadós 1991; Rodríguez 2008a, 2008b); hay que remarcar sin embargo un aspecto que remite al contexto más general de la sociedad colonial tucumana -a las estructuras 
laborales en particular- y que no poco contribuyó al éxito de la campaña de Mercado: el desplome dramático de la mano de obra indígena en las áreas controladas de la provincia (López y Bascary 1996; Noli 2001a, 2003). La apropiación inmediata y masiva de centenares de indios inmediatamente explotables explica el éxito del reclutamiento. Insensiblemente, el Valle de Calchaquí pasó de ser visto solo como una zona de inseguridad para convertirse también en una valiosa reserva de brazos disponibles.

Esto explica en parte el giro radical experimentado a partir de la campaña de 1659 . Con la puesta a disposición de más de siete mil personas, sin contar unas mil piezas repartidas "en caliente" entre los soldados (Larrouy 1923:259), asistimos en poco tiempo al pase a un segundo plano de los imperativos de disciplinamiento y a la imposición de un modelo económico de extracción forzada de mano de obra prometido a mucho futuro en particular en el Chaco. El éxito de la campaña fue subrayado por todos los informes emanados de la provincia: el sucesor de Mercado, Lucas de Figueroa y Mendoza, volvía a proponer explícitamente al rey que los que participasen en las campañas tuviesen un interés directo en ella, porque "a todos les faltaban indios para sus minas y haciendas" (Larrouy 1923:257).

De esta manera, la máquina estatal se transformaba en poderosa fuerza centrífuga que dispersaba a los cautivos cada vez más lejos, según una lógica que se ceñía ante todo a los acuerdos negociados entre las múltiples partes de las tropas de pacificación. A partir de 1659, ya no se dudó ni un instante en negociar el apoyo militar de una ciudad o de un particular a cambio de una retribución en especie, es decir en indios.

\section{Mercado indio: pre-compra y nuevo modelo económico}

La segunda ola de desnaturalizaciones, llevada a cabo a partir de diciembre 1665 fue más arrolladora aún, y no sólo porque los indios se encontraran en una clara posición de debilidad. Dado el éxito de la primera campaña, el reclutamiento de la segunda superó todas las expectativas: se presentaron 540 hombres en armas, cifra que "[...] superaba en número la estimación de las fuerzas posibles" (Mercado y Villacorta 1666, en Larrouy 1923:276).

Nada había sido dejado en olvido: la atribución de las encomiendas se negoció incluso antes del principio de las operaciones. Además de los indios destinados de antemano a los soldados y caudillos, varios contingentes habían sido atribuidos de antemano a las ciudades que habían cofinanciado la campaña. Sin entrar en el detalle, en esta ocasión, se deportaron unas 5.000 personas, sin contar otras 500 piezas (Informe al rey de Lucas de Figueroa y Mendoza, en Larrouy 1923:267). La diferencia entre ambas campañas radica en que el desmembramiento de los grupos desnaturalizados fue infinitamente superior. Si a grandes rasgos, en la campaña de 1659 , se deportaron a los grupos en bloque, respetando más o menos su organización interna, en 1665 la unidad privilegiada para la preventa de la mayoría de las encomiendas era, explícitamente la "familia", concebida sobre el modelo de la familia nuclear (Boixadós 2011a). Obviamente, esta unidad respondía exclusivamente a los imperativos de repartición: había que abastecer a todos los que habían participado en la empresa, con sus armas o pagando soldados. No tenía nada que ver ni con la organización familiar, ni mucho menos con la estructura sociopolítica de las sociedades afectadas. Un seguimiento permite medir la atomización que significó esta deportación en trozos. De las 760 familias, deportadas, 260 fueron destinadas a Córdoba, 350 a La Rioja y Catamarca. Por fin, 150 a Esteco. El empleo de esos indios había sido definido en función de las necesidades de los compradores. Si nos atenemos al caso paradigmático de los desnaturalizados Quilmes, es decir las 260 familias enviadas primero a Córdoba:

- Se quedaron 64 en esta ciudad. De estas, 37 fueron repartidas entre varios individuos como pago de su participación; 18 fueron atribuidas al Cabildo, para el servicio de la acequia y reducidos a unas dos leguas de la ciudad. Siete fueron destinadas al servicio de la Iglesia y de los conventos; 2 fueron entregadas a domicilio a su comprador (González Navarro 2009). - El resto, unas 196 familias fueron conducidas a pie hasta las riberas del Río de la Plata, en una reducción cerrada construida al sur de la ciudad de Buenos Aires: La Exaltación de la Cruz de los Quilmes (Torreblanca 1999 [1696]:111). El caso es conocido, y se suele atribuir a la voluntad de alejar a unos indios particularmente rebeldes. Puede ser, pero el traslado de los Quilmes venía sobre todo a satisfacer un pedido "prepago" de la Audiencia de Buenos Aires. Esta había contribuido al financiamiento de la campaña con el fin de conseguir entre los vencidos la mano de obra que necesitaba -y que no encontraba- para las obras de fortificación del puerto Buenos Aires (Carlón 2007; Palermo y Boixadós 1991).

- Por último, algunas familias que habían huido fueron recapturadas y pasaron a engrosar diferentes encomiendas de Salta, Tucumán, La Rioja o Catamarca.

Las 350 familias desparramadas entre los encomenderos de La Rioja y Catamarca pertenecían a los diversos grupos yocaviles, ingamanas y tucumangastas. Su relocalización había sido pensada en función de las necesidades del cultivo del algodón y de las viñas, dos sectores productivos esenciales para la integración de la región en un espacio económico macro regional. Ello se tradujo en una auténtica atomización en un sinfín de "composiciones": no menos de 39 para la sola ciudad de La Rioja (Boixadós 2011a). Una clara modalidad 


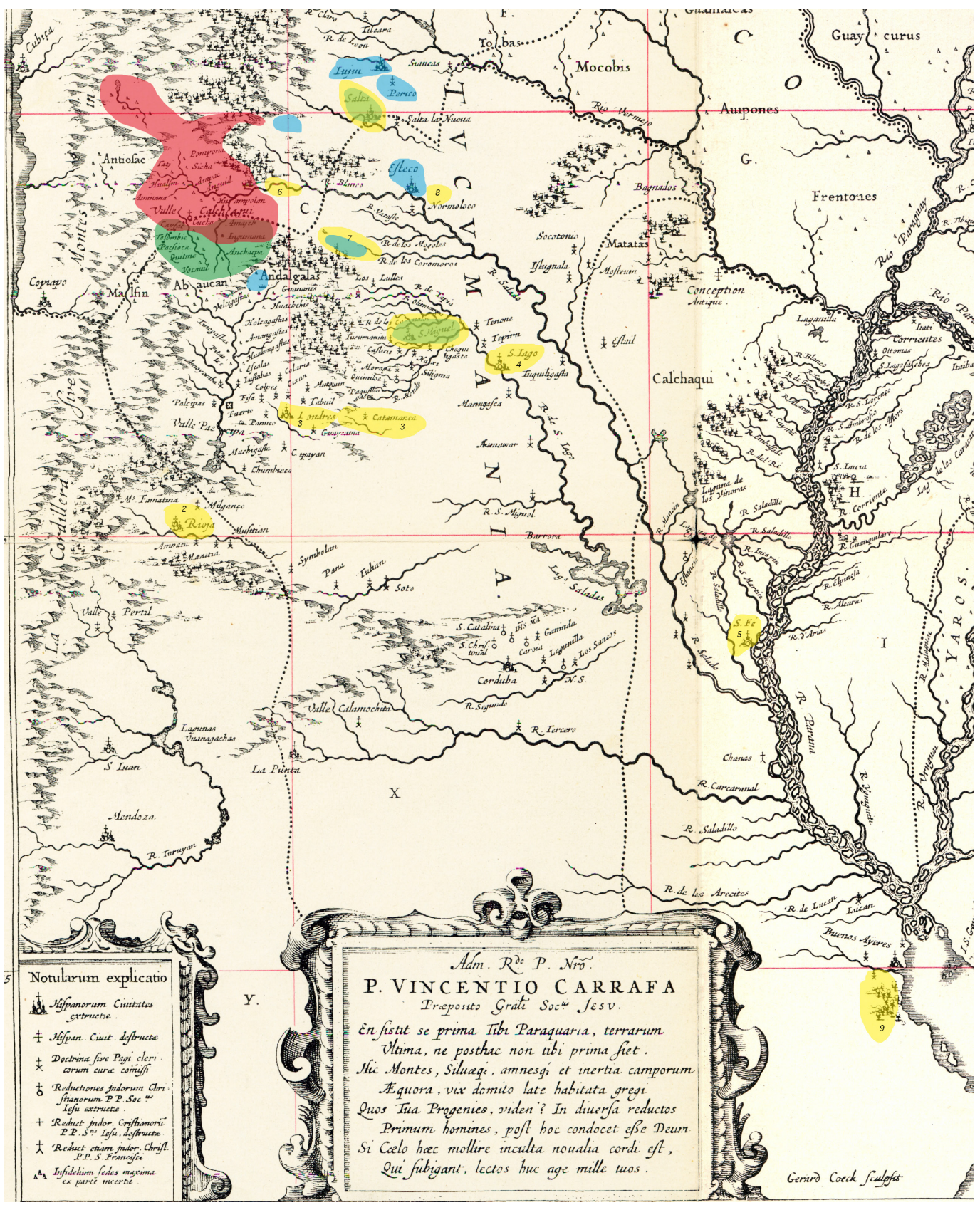

Figura 1. Campaña de desnaturalizaciones de 1665-1666 y relocalizaciones. 1-Quilmes relocalizados en Córdoba (64 familias). 2-3: Yocaviles, Ingamanas, Tucumangastas, Tocpos, Anchacpas (350 familias). 1-2-3-4-5- "piezas", cautivos distribuidos individualmente. 6- Tolombones y Chuschagastas desplazados en el Valle de Guachipas. 7- Tolombones y Colalaos reinstalados, previa negociación, en el Valle de Choromoros. 8Acalianes (150 familias) relocalizados primero en Esteco. Finalmente deportados en la reducción de los Quilmes. 9- Reducción de La Exaltación de la Cruz. Reúne a la mayoría de los Quilmes y, desde 1667, a los Acalianes sobrevivientes, trasladados allí después de su huida de Esteco (unas 40 familias). Fuente: Furlong (1936): "Mapa de las regiones del Paraguay dedicado al Padre Vicente Carrafa", 1647.

NB: la parte en rojo corresponden a la primera campaña (1659), la parte en verde a la segunda (1665-1666). Los puntos en azul corresponden a las primeras relocalizaciones (1659), la partes en amarillo a las segundas (1665-1667).

1665-1666 Deportation and relocalization campaign. 1- Quilmes relocalized in Córdoba (64 families). 2-3: Yocaviles, Ingamanas, Tucumangastas, Tocpos, Anchacpas (350 families). 1-2-3-4-5- "piezas", prisoners distributed individually. 6- Tolombones and Chuschagastas resettled into the Guachipas Valley. 7- Tolombones and Colalaos resettled, after negotiation, into the Choromoros Valley. 8- Acalianes (150 families) first relocalized in Esteco. Finally deported to the "Reducción de los Quilmes". 9- Reducción de La Exaltación de la Cruz. It included the majority of the Quilmes and, since 1667, the remains of the Acalianes, transfered there after their failed escape from Esteco (about 40 families). Source: Furlong (1936): "Mapa de las regiones del Paraguay dedicado al Padre Vicente Carrafa", 1647.

NB: The red parts correspond to the first campaign (1659), the green part to the second one (1665-1666). The blue points indicate the first relocalizations (1659), the yellow ones the second (1665-1667). 
de "colonización por la estancia", según una feliz expresión de Quiroga (2007:74).

\section{Conclusiones: Disciplinar el Espacio, Territorializar la Obediencia}

El fracaso de la política de reducción en el área valliserrano del Tucumán colonial quedaba patente después del último intento de implantación jesuítica y de la catastrófica apuesta de las autoridades por Bohórquez en la segunda mitad de la década de 1650. A pesar de algunos éxitos iniciales en el norte del valle con los grupos llamados pulares, y de otras experiencias de ocupación militarizada más o menos exitosas en el sur de la región considerada, en la estela del "Gran Alzamiento" de los años 1630-1640, los hispano criollos no habían podido ni disciplinar el espacio ni territorializar la obediencia, para retomar los elementos del título del presente trabajo. La ofensiva indígena de 1658 dejaba en claro que el valle Calchaquí seguía siendo un enclave irreductible en el que todos los intentos por extender la soberanía colonial habían quedado sin efecto. Es más, el final bochornoso -y ya definitivo- de la misión jesuítica de Calchaquí (Giudicelli 2013c) así como el regreso de los otrora "domésticos" pulares a una esfera de sospecha significaba una clara agravación de la situación. La política drástica de desnaturalización adoptada entonces como complemento de la pacificación militar constituyó un giro radical en el diagrama colonial. Ya no se trataba de disciplinar a los indios inscribiéndolos en un espacio controlado y cuadriculado dentro del valle para que integrasen por fin la obediencia y cumpliesen con la función económica que se les había asignado. En adelante se procedería al revés: puesto que no se podía territorializar la obediencia, no se podía adecuar la obediencia con una territorialidad colonial, el disciplinamiento del espacio pasaría por una desterritorialización de los grupos vencidos, una relocalización en un espacio -o mejor dicho en unos espacios- ya disciplinados, fuera de su natural, y una posterior instalación de estructuras de producción coloniales en un territorio vaciado, estancias y haciendas en particular. Es de notar por cierto que décadas después varios contingentes de indígenas calchaquíes serían reinstalados en el valle... pero ya dentro de esos establecimientos coloniales (Cruz 1997; Quintian 2008; Rodríguez 2008).

Sin embargo, creemos necesario recalcar un aspecto coyuntural mayor en la política radical adoptada por el gobernador Mercado y Villacorta, que respondía a dos imperativos en los que se mezclaban intricadamente los aspectos estratégicos y económicos. Por un lado se impuso como la única forma de vencer la resistencia ya secular de los calchaquíes, al apartarlos de sus redes de alianza $y$ al alejarlos de una tierra en la que manejaban mucho mejor que sus enemigos los distintos pisos ecológicos, por lo que podían seguir resistiendo indefinidamente (Quiroga 2010:203). Por otro lado, la atomización de los grupos desterrados en una miríada de encomiendas y de piezas respondía a la demanda cada vez más fuerte de mano de obra para los establecimientos agrícolas o las obras públicas de las ciudades del Tucumán y más allá. El espacio indisciplinado e inobediente del valle de Calchaquí constituía ya una valiosa reserva de piezas y brazos, en contraste con las zonas controladas de la provincia, en las que la población indígena había alcanzado su nadir.

Los estudios regionales más finos (Cruz 199092; Fandos 2007; López de Albornoz 1990, 1991; López y Bascary 1996; Rodríguez 2008a, 2008b) han demostrado sin equívoco que la tan recurrentemente afirmada desaparición de los grupos originarios de los Valles es un espejismo que tiene más que ver con un "efecto de fuentes" (los informes del gobernador, destinados a demostrar el éxito de su actuación) y la creencia cuidadosamente construida desde la segunda mitad del siglo XIX de que los indios en general habían desaparecido (Escolar 2007; Giudicelli 2011b). Como lo recuerda oportunamente Rodríguez (2017), la estrategia de resistencia implementada por quienes pudieron adoptarla consistió en mantener una doble residencia en su lugar de destierro, fuera del valle, y en sus antiguas tierras. Desnaturalizados y sometidos, varios grupos lograron sin embargo retomar pie en el valle, de forma negociada, clandestina, o incluso forzada, ya que varios fueron reinstalados décadas después de su expulsión en las grandes haciendas que se habían instalado en sus antiguas tierras. De esta manera, consiguieron asegurar, aunque con una autonomía muy menguada, su reproducción social en tanto entidad colectiva, y preservar una memoria también colectiva. De modo que si la política drástica de desnaturalización logró en gran medida disciplinar el espacio -por el vacío- e imponer la obediencia -fuera del valle-, habría que matizar el alcance absoluto de la reterritorialización de los vencidos. $\mathrm{Ni}$ desaparecieron los indios, ni se perdió el vínculo histórico con su tierra. Un elemento muy de tomar en cuenta en estos tiempos de supuesta "re-emergencia" en los que se llega hasta negar la existencia de colectivos indígenas y cuestionar la legitimidad de su memoria. 


\section{Referencias Citadas}

\section{Archivos}

AHPC: Archivo Histórico de la Provincia de Córdoba AGI: Archivo General de Indias

AGN: Archivo General de la Nación (Buenos Aires)

AHT: Archivo Histórico de Tucumán

BNBA-García Viñas: fondo García Viñas de la Biblioteca Nacional de Buenos Aires.

\section{Fuentes impresas}

Carta Anua de 1632-1634. Cartas Anuas de la provincia jesuítica del Paraguay. Academia Nacional de la Historia, 1990, Buenos Aires.

Cortesão, J. 1952. Manuscritos da Coleção de Angelis. Biblioteca Nacional do Río de Janeiro. Río de Janeiro.

Larrouy, A (comp.) 1923. Documentos del Archivo de Indias para la Historia del Tucumán, Vol. 1. Santuario de Señora del Valle, I.L.J. Rosso y Cía, Buenos Aires.

Levillier, R. (comp.) 1926. Papeles Eclesiásticos del Tucumán Ed. De Juan Pueyo, 2 vol., Madrid.

Levillier, R. (comp.) 1930. Nueva Crónica de la Conquista del Tucumán, Buenos Aires-Varsovia.

Lozano, P. 2010 [1745]. Historia de la Conquista del Paraguay, Tucumán y Río de la Plata. AHN, Buenos Aires.

Moyano Aliaga, A. 1991. La Rioja. Revelaciones Documentales acerca de su Fundación. Córdoba. Ed. de la Junta Provincial de historia de Córdoba, Córdoba.

Mujía, R. 1914. Bolivia Paraguay, Anexos, vol. III, La Paz.

Pastells, P. (comp.) 1912. Historia de la Compañía de Jesús en la Provincia del Paraguay. Victoriano Suárez, Madrid.

Rodríguez Molas, R. (comp.) 1985. Los sometidos de la conquista. CELA, Buenos Aires.

Torreblanca, H. 1999 [1696]. Relación Histórica de Calchaquí. AGN, Buenos Aires.

\section{Fuentes publicadas}

Boixadós, R. 2011a. El fin de las guerras calchaquíes. La desnaturalización de la nación yocavil a La Rioja (1667). Corpus Archivos Virtuales de la Alteridad Americana (on line) http://journals.openedition.org/corpusarchivos/920

Boixadós, R. 2011b. Rebeldes, soldados y cautivos. Etnografía de un episodio en la frontera de guerra del valle Calchaquí (1634). En Resistencias, Conflictos y Negociaciones. El Valle Calchaquí desde el Período Prehispánico hasta la Actualidad, compilado por L. Rodríguez, pp. 93-122. Prohistoria Ediciones, Rosario.

Carmignani, L. 2013. Las visitas de los tenientes de naturales a los partidos de pueblos de indios de la gobernación del Tucumán. (1606-1607). Corpus. Archivos Virtuales de la Alteridad Americana Vol 3, No 2, Julio/Diciembre 2013. http:// journals.openedition.org/corpusarchivos/548

Cruz, R. 1990-92. La "construcción" de identidades étnicas en el Tucumán colonial: los amaichas y los tafíes en el debate sobre su "verdadera" estructura étnica. Relaciones de la Sociedad Argentina de Antropología XVIII:65-92.

Cruz, R. 1997. El fin de la "ociosa libertad". Calchaquíes desnaturalizados a la jurisdicción de San Miguel de Tucumán en la segunda mitad del siglo XVII. En El Tucumán Colonial y Charcas, compilado por A.M. Lorandi, pp. 215-261. FFyLUBA, Buenos Aires.

De la Orden de Peracca, G. 2006. Pueblos Indios de Pomán. Catamarca (Siglos XVII a XIX). Editorial Dunken, Buenos Aires.

Doucet, G. 1982. Notas sobre el yanaconazgo en el Tucumán. Revista de Investigaciones Jurídicas 6 (6):263-299. México, D.F.

Doucet, G. 1988. Sobre cautivos de guerra y esclavos indios en el Tucumán. Revista de Historia del Derecho 16:59-152.

Escolar, D. 2007. Los Dones Étnicos de la Nación. Identidades Huarpe y Modos de Producción de Soberanía en Argentina. Prometeo, Buenos Aires.

Fandos, C. 2007. Estructura y transferencia de la propiedad comunal de Colalao y Tolombón (provincia de Tucumán) en la segunda mitad del siglo XIX. Mundo Agrario. Revista de Estudios Rurales 7 (14).

Farberman, J. y R. Gil Montero (eds.) 2002. Los Pueblos de Indios del Tucumán Colonial: Pervivencia y Desestructuración. EdiUnju, Universidad Nacional de Quilmes, Quilmes.

Furlong, G. 1936. Cartografía Jesuítica del Río de la Plata. Jacobo Peuser, Buenos Aires.

Giudicelli, C. 2007. Encasillar la frontera. Clasificaciones coloniales y disciplinamiento del espacio en el área diaguitocalchaquí (S. XVI-XVII). Anuario IEHS 22:161-212.

Giudicelli, C. 2011a. La raya de los pulares. Pouvoir colonial et quadrillage de l'espace social dans le Valle de Calchaquí. En Les Indiens des Frontières Coloniales. Amérique Australe, XVIe au XXe Siècle, editado por L. Capdevila, J.P. Obregón Iturra y N. Richard, 27-58. PUR, Rennes.

Giudicelli, C. 2011b. Lectura de las ruinas. La fabricación de antepasados aceptables en el noroeste argentino (Siglos XVIXVII/siglo XIX). En Fronteras y Sensibilidades, editado por S. Bernabéu Albert y F. Langue, pp. 115-139. Doce Calles, Madrid.

Giudicelli, C. 2013a. Calibay o la tempestad. Debate en torno a un documento "indígena" de la Salta primitiva. Corpus Vol. 3 $\mathrm{n}^{\circ} 1$. http://journals.openedition.org/corpusarchivos/336

Giudicelli, C. 2013b. Una milicia de vencidos: los calchaquíes frente a las primeras "invasiones mocovíes" (final del S. XVII-principios del XVIII). Los pródromos de la guerra en la frontera chaqueña del Tucumán. En El Primer Siglo XVIII en Hispanoamérica, editado por B. Lavallé, pp. 221-245. Méridiennes, Toulouse.

Giudicelli, C. 2013c. Falar a língua do inimigo. A solidão do missionário nas terras calchaquís. Tempo. Rio de Janeiro. http:// www.historia.uff.br/tempo/site/wp-content/uploads/2013/12/ v19n35a04.pdf

Giudicelli, C. 2015. La prise de Córdoba de Calchaquí (décembre 1562). Émergence d'un ennemi intérieur indien (Tucumán, Nord-ouest argentin). En La Bataille, du Fait D’Armes au Combat Idéologique (XIe-XIXe Siècles), editado por A. Boltanski, F. Mercier e Y. Lagadec, pp. 93-108. PUR, Rennes.

González Navarro, C. 2009. La incorporación de los indios desnaturalizados del valle Calchaquí y de la región del Chaco a la jurisdicción de Córdoba del Tucumán. Una mirada desde la visita del oidor Antonio Martines Luxan de Vargas, 1692-1693. Jahrbuch für Lateinamerikas 46:231-259. 
López de Albornoz, C. 1990. Las desnaturalizaciones Calchaquíes y sus efectos en las poblaciones trasladadas al Valle de Choromoros. Anuario de Estudios Americanos XLVII:29-42.

López de Albornoz, C. 1991. Las poblaciones aborígenes del Valle de Choromoros en el siglo XVII. Memoria Americana 1:29-56.

López de Albornoz, C. y A. Bascary 1996. Pueblos indios de Colalao y Tolombón: Identidad Colectiva y Articulación étnica y social (siglos XVII-XIX). Humanitas 27. Revista de la Facultad de Filosofía y Letras UNT.

Lorandi, A.M. (comp.) 1997. El Tucumán Colonial y Charcas FFyL - UBA, Buenos Aires.

Lorandi, A.M. 1997 De Quimeras, Rebeliones y Utopías: la Gesta del Inca Pedro Bohorques PUCP, Lima.

Lorandi, A.M. y R. Boixadós 1987-1988. Etnohistoria de los Valle Calchaquis. Runa17-18:263-420.

Montes, A. 1961. El gran alzamiento diaguita. Revista del Instituto de Antropología 1:81-159. Universidad del Litoral, Rosario.

Morales Padrón, F. 1979. Teoría y Leyes de la Conquista. C.I.C., Madrid.

Noli, E. 2001. La declinación de la población indígena de la jurisdicción de San Miguel de Tucumán. 1600/1680. En América Bajo los Austrias. Economía, Cultura y Sociedad, editado por O. Noejovich, pp. 165-192. PUCP, Lima.

Noli, E. 2003. Pueblos de indios, indios sin pueblos: los calchaquíes desnaturalizados en la visita de Luján de Vargas de 1693 a San Miguel de Tucumán. Anales Nueva Época 6: 330-363.

Page, C. 2004. Los ejidos como espacio comunal de la ciudad de Córdoba del Tucumán. Revista de Indias vol. LXIV (232):635-650.

Piossek Prebisch, T. 1999 [1976]. Pedro Bohórquez, El Inca del Tucumán 1656-1659. Magma ed., Catamarca.

Quintián, J.I. 2008 Articulación política y etnogénesis en los Valles Calchaquíes: los Pulares durante los siglos XVII y XVIII. Andes 19:299-325.
Quiroga, L. 2007. Arquitectura de la vivienda prehispánica y colonial. Una perspectiva comparativa en el área valliserrana del Noroeste argentino, En Arquitectura Vernácula en el Mundo Ibérico, coordinado por A.M. Aranda Bernal, pp.71-77. Universidad Pablo de Olavide, Sevilla.

Quiroga, L. 2010. En sus huaycos y quebradas: formas materiales de la resistencia en las tierras de malfín. Memoria Americana 182:185-209.

Quiroga, L. 2012. Las granjerías de la tierra: actores y escenarios del conflicto colonial en el valle de Londres (gobernación del Tucumán, 1607-1611). Surandino Monográfico, segunda sección del Prohal Monográfico, Vol. II, ${ }^{\circ} 1$.

Rodríguez, L.B. 2008a. Después de las Desnaturalizaciones: Transformaciones Socio-económicas y Étnicas al Sur del Valle Calchaquí. Santa María, Fines del Siglo XVII- Fines del siglo XVIII. Antropofagia, Buenos Aires.

Rodríguez, L.B. 2008b. Los Ingamana en Andalgalá a principios del siglo XVIII: Notas sobre la memoria y la identidad. Andes 19:279-298.

Rodríguez, L.B (comp.) 2011. Resistencias, Conflictos y Negociaciones. El Valle Calchaquí desde el Período Prehispánico hasta la Actualidad. Prohistoria ed., Rosario.

Rodríguez,L.B. 2017. Efectos imprevistos de las desnaturalizaciones del valle Calchaquí. El "doble asentamiento" como estrategia de resistencia. Chungara Revista de Antropología Chilena 49:601612.

Rodríguez Molas, R. (comp.) 1985. Los Sometidos de la Conquista. CELA Buenos Aires.

Schaposchnik, A.E. 1994. Aliados y parientes. Los diaguitas rebeldes de Catamarca durante el gran alzamiento. Histórica 18 (2):383-416.

Sosa Miatello, S. y A.M. Lorandi 1991. El precio de la libertad. Desnaturalización y traslados de indios rebeldes en el siglo XVII. Memoria Americana I (1):7-28.

Vázquez, F.I. 2011. Territorialidad y reproducción social: los tinogasta en Belén, Catamarca, durante el siglo XVIII. Memoria Americana, n.19-1. http://www.scielo.org.ar/scielo. php? script=sci_arttext\&pid=S1851-37512011000100003\&ln $\mathrm{g}=\mathrm{es} \& \mathrm{nrm}=\mathrm{iso}>$
1 Este tema es de suma importancia. Solo será evocado tangencialmente en el presente artículo. Para un estudio reciente y pormenorizado, consúltese Ródríguez (2017).

2 AHPC-Escribanía I-71-exp. 6. "Contra Andrés de Frías y Sandoval", F 185 Vta.

3 Sobre el estado caótico de la región, véase BNBA, García Viñas, 186:3920, "Carta del gobernador Barraza y Cárdenas 29-05-1604".

4 Carta a S.M. del gobernador Juan Ramírez de Velasco, 2010-1591, en Levillier (1930 III:339-342).

5 ARSI, Paraquaria 4-1, F 110 f, Informe adjunto al catálogo trienal de 1626 por el Provincial Nicolás Mastrilli Durán.

6 BNBA, García Viñas, $\mathrm{n}^{\circ}$ 4134, Carta del gobernador Alonso de Rivera 10-03-1611.
AHT, Protocolos. Vol. 2, Fs 281-291 "Renuncias a indios de encomiendas en la corona (fundación de una ciudad en el Valle de Calchaquí: Nuestra Señora de Guadalupe, sitio de Samalamahao). 1631; carta del gob. Felipe de Albornoz al rey, 29-04-1631, en Larrouy (1923:411-417).

$8 \quad[.$.$] para que no hiciessen en saliendo los españoles$ lo que hicieron en el pueblo de Atapsi, y para que sus encomenderos tuviessen de ellos algún interés y servicio, y en particular para el seguro de esta provincia, y que no volviessen en adelante a obligar a semejantes entradas y gastos, como se podía temer no dejándoles algún presidio de españoles que los pusiesse en temor y freno [...] me fue pedido por todos reedificase en aquel mesmo paraje la ciudad antigua que edificó en él el gobernador Gonzalo de 
Abrego". Carta del gob. Felipe de Albornoz" 01-03-1633, en Larrouy (1923:75).

[...]para que no hiciessen en saliendo los españoles lo que hicieron en el pueblo de Atapsi, y para que sus encomenderos tuviessen de ellos algún interés y servicio, y en particular para el seguro de esta provincia, y que no volviessen en adelante a obligar a semejantes entradas y gastos, como se podía temer no dejándoles algún presidio de españoles que los pusiesse en temor y freno $[\ldots]$ me fue pedido por todos reedificase en aquel mesmo paraje la ciudad antigua que edificó en él el gobernador Gonzalo de Abrego". Carta del gob. Felipe de Albornoz" 01-03-1633, en Larrouy (1923:75).

9 BNA-Fondo García Viñas 4083, Carta al rey del gob. del Tucumán, don Alonso de Rivera 11-04-1610; Carta del Virrey conde de Montesclaros a SM. contestando una $\mathrm{RC}$ del 5-07-1609 en que se le manda informe qué provincia es la de Guairá. Da curiosas noticias geográficas (Río de la Plata, Chaco, llanos de Manso, provincia de los Guaycurús, 18-03-1610, en Mujía (1914:268-282).

10 Carta del gob. Francisco de Albornoz, 16-03-1634, en Larrouy (1923:135-136).
11 Para el efecto, se había incluso construido otro fuerte y destinado una tropa de cincuenta hombres para impedir el paso hacia las nuevas reducciones de pulares y la ciudad de Salta. AGI, Charcas, 56. Certificación de los servicios de Alvaro de Padilla Aguilera por el maese de campo Pedro de Olmos de Aguilera y el capitán don Alonso de Ribera sargento mayor y Martín de Pardiñas alcalde ordinario de esta ciudad y fuerte de Nuestra Señora de Guadalupe, 12-06-1631.

12 AHPC, Escr. 2a, leg. 6, T. I, exp. 2, Servicios del maese de campo Ramírez de Contreras.

13 Carta anua de 1632-1634 Cartas Anuas de la provincia jesuitica del Paraguay (1990:70).

14 AHPC, Escr. 2a, leg. 6, T. I, exp. 2. Servicios del maese de campo Ramírez de Contreras; parcialmente en Montes (1961:140-142).

15 Carta del gobernador Alonso de Mercado y Villacorta, Buenos Aires, 05-05-1661, en Larrouy 1923:237.

16 AGI, Charcas 122, exp. 44. Técnicamente, no se trataba de esclavos, más bien de lo que se llamaba depósito: las piezas eran condenadas a servir a su amo durante un tiempo variable (diez, quince, veinte años). En los hechos, la diferencia era muy tenue. 